\title{
PEMANFAATAN TEKNOLOGI INFORMASI DALAM GERAKAN PEMBERDAYAAN KELOMPOK BURUH TANI DAN NELAYAN
}

\author{
Hironimus Leong ${ }^{1}$, Cecilia Titiek Murniati ${ }^{2}$ \\ 1. Teknik Informatika, Fakultas Ilmu Komputer, Universitas Katolik Soegijapranata \\ 2. Sastra Inggris, Fakultas Bahasa dan Seni, Universitas Katolik Soegijapranata \\ Email: marlon.leong@unika.ac.id, c_murniati@unika.ac.id
}

\begin{abstract}
Abstrak
Program pengabdian masyarakat ini bertujuan untuk memperluas gerakan pemberdayaan komunitas buruh tani dan nelayan, mendiseminasi kegiatan Lembaga Pendampingan Buruh Tani dan Nelayan (LPUBTN) kepada khalayak luas dengan memanfaatkan teknologi informasi yang tersedia, meningkatkan literasi teknologi para pengelola dan relawan yang berkecimpung dalam kegiatan pendampingan LPUBTN, serta menjalin kemitraaan yang strategis antara Unika Soegijaranata dan Keuskupan Agung Semarang melalui pemanfatan teknologi informasi dan media sosial. Data untuk membuat situs dan mengintegrasikan media sosial dalam situs didapat dengan wawancara dengan pengelola dan relawan. Saat ini situs sudah berfungsi dan pengelola situs sudah menggunakan program ini untuk memperbarui kegiatan pendampingan. Namun demikian, di masa mendatang, situs dan media sosial yang digunakan oleh LPUBTN harus di evaluasi ulang untuk mengetahui apakah program kerja lembaga diketahui banyak orang dan apakah situs ini berpengaruh terhadap diseminasi informasi lembaga tersebut.
\end{abstract}

Kata kunci: teknologi informasi, media sosial, pemberdayaan, buruh tani, nelayan.

\begin{abstract}
Title: Utilizing information technology in the movement of community empowerment for farmers and fishermen.

This community service program aims to expand the movement of community empowerment for farmers and fishermen, disseminate the activities of Center for the Community Empowerment for Farmers and Fishermen (LPUBTN) to society by utilizing the available information technology, improve the technology literacy of the managers and volunteers who are involved in the mentoring activities of LPUBTN, and establish strategic partnerships between Unika Soegijaranata and Semarang Archdiocese through the utilization of information technology and social media. The data to create the LPUBTN site and integrate social media into the site were obtained through interviews with the managers and volunteers. Currently the site is running smoothly. The site managers already use this program to update the mentoring activities. However, in the future, websites and social media used by LPUBTN must be re-evaluated to determine whether they can reach wider audience and are effective as a tool for information dissemination.
\end{abstract}

Keywords: information technology, social media, empowerment, farmers, fishermen. 


\section{PENDAHULUAN}

Menurut Biro Pusat Statistik (2014) ada 11,47 masyarakat Indonesia berada di bawah garis kemiskinan. Upah yang diterima buruh peternakan dan perikanan adalah Rp. 1.144.000 per bulan (Badan Pusat Statistik [BPS], 2016a) sedangkan buruh tani Rp. 1.125.000 per bulan (BPS, 2016b). Dengan harga barang yang semakin meningkat, buruh tani dan nelayan harus berjuang keras agar mereka bisa mencukupi kebutuhan sehari-hari. Di samping itu, komunitas buruh tan I dan nelayan sering kali menjadi pihak yang terpinggirkan karena banyak pejabat pemerintah yang lebih berpihak pada investor asing (Abidin, 2016). Berbekal semangat Mgr. Soegijapranata, option for the poor, Universitas Katolik Soegijapranata melalui lembaga penelitian dan pengabdian masyarakat berkeingan untuk mendorong gerakan pemberdayaan masyarakat terutama masyarakat miskin, terpinggirkan, dan difabel di sekitar universitas. Dalam kegiatan pengabdian ini, tim ingin memfokuskan pada komunitas buruh tani dan nelayan yang sebelum ini jarang pernah terjamah oleh kegiatan pengabdian masyarakat.

Dalam kegiatan ini, tim bekerja sama dengan Keuskupan Agung Semarang terutama melalui salah satu unit yang bergerak dalam pemberdayaan buruh tani nelayan yaitu Lembaga Pendamping Buruh Tani dan Nelayan (LPUBTN). Lembaga ini sejak awal bertujuan sebagai gerakan untuk memberdayakan komunitas buruh tani dan nelayan agar mereka mampu hidup layak dan mandiri. Pendirian lembaga ini disemangati oleh nilai-nilai Romo John Dijkstra, SJ yang menekankan pentingnya keterlibatan semua orang dalam membangun bangsa dan negara. Dengan kata lain, gerakan pemberdayaan masyarakat akan mempunyai gaung yang lebih keras jika semakin banyak masyarakat umum yang mengetahui kegiatan ini dan berpartisipasi dalam berbagai ragam kegiatan pendampingan buruh tani dan nelayan di Semarang dan sekitarnya.

Gerakan pemberdayaan ini tidak akan berjalan dengan baik jika kegiatan yang dilakukan tidak tersampaian pada masyarakat luas dengan baik. Masyarakat tidak akan mengetahui upaya apa saja yang telah dilaksanakan oleh lembaga dan akibatnya gerakan ini tidak mendapat dukungan banyak dari berbagai pihak. Karena itu, untuk mendiseminasi kegiatan pendampingan kelompok buruh tani dan nelayan dan untuk mendapatkan dukungan yang lebih luas, lembaga ini berkerjasama dengan Unika Soegijapranata dalam hal pemanfaatan teknologi informasi. 


\title{
PEMANFAATAN TEKNOLOGI INFORMASI DALAM GERAKAN PEMBERDAYAAN KELOMPOK BURUH TANI DAN NELAYAN
}

\author{
Hironimus Leong ${ }^{1}$, Cecilia Titiek Murniati ${ }^{2}$ \\ ${ }^{1}$ Teknik Informatika, Fakultas Ilmu Komputer, ${ }^{2}$ Sastra Inggris, Fakultas Bahasa \&Seni \\ Universitas Katolik Soegijapranata \\ Email: marlon.leong@unika.ac.id, c_murniati@unika.ac.id
}

\begin{abstract}
ABSTRAK
Program pengabdian masyarakat ini bertujuan untuk memperluas gerakan pemberdayaan komunitas buruh tani dan nelayan, mendiseminasi kegiatan Lembaga Pendampingan Buruh Tani dan Nelayan (LPUBTN) kepada khalayak luas dengan memanfaatkan teknologi informasi yang tersedia, meningkatkan literasi teknologi para pengelola dan relawan yang berkecimpung dalam kegiatan pendampingan LPUBTN, serta menjalin kemitraaan yang strategis antara Unika Soegijaranata dan Keuskupan Agung Semarang melalui pemanfatan teknologi informasi dan media sosial. Data untuk membuat situs dan mengintegrasikan media sosial dalam situs didapat dengan wawancara dengan pengelola dan relawan. Saat ini situs sudah berfungsi dan pengelola situs sudah menggunakan program ini untuk memperbarui kegiatan pendampingan. Namun demikian, di masa mendatang, situs dan media sosial yang digunakan oleh LPUBTN harus di evaluasi ulang untuk mengetahui apakah program kerja lembaga diketahui banyak orang dan apakah situs ini berpengaruh terhadap diseminasi informasi lembaga tersebut.
\end{abstract}

Kata kunci: teknologi informasi, media sosial, pemberdayaan, buruh tani, nelayan.

\section{ABSTRACT \\ Utilizing Information Technology In The Movement Of Community Empowerment For Farmers And Fishermen.}

This community service program aims to expand the movement of community empowerment for farmers and fishermen, disseminate the activities of Center for the Community Empowerment for Farmers and Fishermen (LPUBTN) to society by utilizing the available information technology, improve the technology literacy of the managers and volunteers who are involved in the mentoring activities of LPUBTN, and establish strategic partnerships between Unika Soegijaranata and Semarang Archdiocese through the utilization of information technology and social media. The data to create the LPUBTN site and integrate social media into the site were obtained through interviews with the managers and volunteers. Currently the site is running smoothly. The site managers already use this program to update the mentoring activities. However, in the future, websites and social media used by LPUBTN must be reevaluated to determine whether they can reach wider audience and are effective as a tool for information dissemination.

Keywords: information technology, social media, empowerment, farmers, fishermen 


\section{LATAR BELAKANG}

Menurut Biro Pusat Statistik atau BPS (2014), ada 11,47 masyarakat Indonesia berada di bawah garis kemiskinan. Upah yang diterima buruh peternakan dan perikanan adalah Rp. 1.144.000 per bulan (BPS, 2016a) sedangkan buruh tani Rp. 1.125 .000 per bulan (BPS, 2016b). Dengan harga barang yang semakin meningkat, buruh tani dan nelayan harus berjuang keras agar mereka bisa mencukupi kebutuhan sehari-hari. Di samping itu, komunitas buruh tani dan nelayan sering kali menjadi pihak yang terpinggirkan karena banyak pejabat pemerintah yang lebih berpihak pada investor asing (Abidin, 2016). Berbekal semangat Mgr. Soegijapranata, option for the poor, Universitas Katolik Soegijapranata melalui Lembaga Penelitian dan Pengabdian kepada Masyarakat (LPPM) berkeinginan untuk mendorong gerakan pemberdayaan masyarakat terutama masyarakat miskin, terpinggirkan, dan difabel di sekitar universitas. Dalam kegiatan pengabdian ini, tim ingin memfokuskan pada komunitas buruh tani dan nelayan yang sebelum ini jarang pernah terjamah oleh kegiatan pengabdian masyarakat.

Dalam kegiatan ini, tim bekerja sama dengan Keuskupan Agung Semarang (KAS) terutama melalui salah satu unit yang bergerak dalam pemberdayaan buruh tani nelayan yaitu Lembaga Pendamping Buruh Tani dan Nelayan (LPUBTN). Lembaga ini sejak awal bertujuan sebagai gerakan untuk memberdayakan komunitas buruh tani dan nelayan agar mereka mampu hidup layak dan mandiri. Pendirian lembaga ini disemangati oleh nilai-nilai Romo John Dijkstra, SJ yang menekankan pentingnya keterlibatan semua orang dalam membangun bangsa dan negara. Dengan kata lain, gerakan pemberdayaan masyarakat akan mempunyai gaung yang lebih keras jika semakin banyak masyarakat umum yang mengetahui kegiatan ini dan berpartisipasi dalam berbagai ragam kegiatan pendampingan buruh tani dan nelayan di Semarang dan sekitarnya.

Gerakan pemberdayaan ini tidak akan berjalan dengan baik jika kegiatan yang dilakukan tidak tersampaikan pada masyarakat luas dengan baik. Masyarakat tidak akan mengetahui upaya apa saja yang telah dilaksanakan oleh lembaga dan akibatnya gerakan ini tidak mendapat dukungan banyak dari berbagai pihak. Karena itu, untuk mendiseminasi kegiatan pendampingan kelompok buruh tani dan nelayan dan untuk mendapatkan dukungan yang lebih luas, lembaga ini berkerjasama dengan LPPM Unika Soegijapranata dalam hal pemanfaatan teknologi informasi. Tujuan utama program pengabdian masyarakat ini adalah untuk

a. Memperluas gerakan pemberdayaan komunitas buruh tani dan nelayan.

b. Mendiseminasi kegiatan LPUBTN kepada khalayak luas dengan memanfaatkan teknologi informasi yang tersedia.

c. Meningkatkan literasi teknologi para pengelola dan relawan yang berkecimpung dalam kegiatan pendampingan LPUBTN.

d. Mempererat kerjasama strategis antara Unika Soegijapranata dengan Keuskupan Agung Semarang.

\section{MASALAH}

LPBTN berawal dari gagasan Mgr. Albertus Soegijapranata SJ (mantan Uskup Agung Semarang dan pahlawan nasional) bersama John Dijkstra SJ (alm) yang menekankan pentingnya keterlibatan semua pihak dalam membangun bangsa dan negara. Karena itu dibentuklah Yayasan Pembimbing Usaha-usaha Buruh dan Tani (YPUBT), 19 September 1960. Pembentukan YPUBT bertujuan untuk memberi pendampingan dan pemberdayaan masyarakat terhadap pelaku usaha sosial ekonomi terutama yang berasal dan bergerak dalam lapangan perburuhan, pertanian dalam 
arti yang seluas-luasnya. Pembentukan YPUBT ini sangat relevan terutama pada masa krisis ekonomi dimana jumlah masyarakat miskin meningkat tajam. Pada awalnya YPUBT melakukan pendampingan bagi para buruh dan petani. Kemudian YPUBT melebarkan kegiatan pendampingan di kawasan nelayan. Setelah itu, YPUBT berubah nama menjadi Yayasan Pendamping Usaha-usaha Butuh Tani Nelayan (YPUBTN) pada tahun 1997. Nama ini kemudian berubah lagi dan menjadi Lembaga Pendamping Usaha Buruh Tani Nelayan (LPUBTN).

Dalam proses pendampingan ini, LPUBTN ingin mewujudkan pemikiran John Dijkstra dalam menggerakan semua pihak untuk ikut terlibat dalam gerakan membangun bangsa dan negara melalui bimbingan usaha buruh tani dan nelayan salah satu cara yang ditempih adalah melalui pemanfaatan media teknologi informasi.

\section{METODE PELAKSANAAN}

Dalam kegiatan pengabdian masyarakat ini, tim menggunakan: a) penerapan IPTEK bagi masyarakat, dan b) membuat laman kegiatan LPUBTN. Selain itu, agar proses update laman berjalan setelah kegiatan pengabdian masyarakat selasai, tim memberikan pelatihan aplikasi blog bagi karyawan LPUBTN yang akan bertanggung jawab untuk mengisi dan memperbarui data dalam laman.

\section{Teknik Pengumpulan Data}

Data untuk kegiatan masyarakat ini didapatkan dari wawancara dengan pihak pengelola dan relawan LPUBTN. Dalam wawancara tersebut, tim menggali informasi mengenai tujuan pembuatan laman dan akun media sosial, informasi apa saja yang akan di muat di dalamnya, media apa saja yang akan dimasukkan, dan tampilan yang diinginkan. Di samping wawancara, tim juga mendapatkan data untuk laman dan akun sosial dari dokumen LPUBTN, misalnya dokumen visi dan misi, foto kegiatan, dan dokumen lain yang berkaitan erat dengan sejarah dan pencapaian lembaga.

\section{Teknik Analisis Data}

Data yang terkumpul dari hasil wawancara ditranskrip dan digunakan untuk membuat laman dan akun media sosial. Permintaan pengelola dan relawan PLUBTN digabungkan dalam usulan draft.

\section{Lokasi, waktu, dan durasi kegiatan.}

Lokasi; Pelatihan pengelolaan situs dilakukan di Wisma Pojok, Jalan Srigunting Semarang.

Waktu; Rentang waktu pelaksanaan kegiatan ini adalah bulan Juni sampai September. Pada bulan Juni tim mengadakan wawancara dengan pengelola dan relawan dari wilayah Semarang, Yogyakarta, Kedu dan Surakarta untuk mengetahui apa yang mereka inginkan dan butuhkan dalam suatu situs dan media sosial. Pada bulan Juli, tim mulai merancang desain dasar situs dan menu utama di situs. Desain disesuaikan dengan permintaan pengelola dan masukan dari para relawan. Pada bulan Agustus, tim memberi pelatihan pengoperasian situs bagi 14 orang yang akan bertanggung jawab terhadap pembaruan berita di situs LPUBTN. Sedangkan pada bulan September, situs LPUBTN ditayangkan dan beroperasional dengan resmi.

Durasi kegiatan; Wawancara dengan pengelola dan relawan berlangsung pada tanggal 3 Juni 2016, sedangkan pembuatan situs berlangsung sebulan penuh pada bulan Juli. Pelatihan untuk pengelolaan situs dilaksanakan sehari pada hari Sabtu tanggal 20 Agustus 2016. 


\section{HASIL DAN PEMBAHASAN}

a. Laman LPUBTN (http://lpubtn.web.id/)

Gambar 1 di bawah menunjukkan halaman depan laman LPUBTN. Dalam wawancara, pengurus lembaga dan sukarelawan mengatakan bahwa mereka ingin menggunakan situs ini untuk mendiseminasikan nilai-nilai dan semangat Romo Djikstra untuk memberdayakan masyarakat yang terpinggirkan, terutama buruh tani nelayan yang ada di wilayah Keuskupan Semarang. Karena itu, laman LPUBTN dirancang sedemikian rupa sehingga masyarakat luas mendapatkan informasi yang baik mengenai visi, misi, tujuan, dan program kerja lembaga (pada laman LPUBTN KAS) di samping informasi lengkap mengenai kegiatan pendampingan lembaga ini yang terletak pada halaman terdepan (HOME). Karena pengelola lembaga berkeinginan untuk melebarkan wilayah gerakan pemberdayaan masyarakat, maka laman WILAYAH dibuat untuk tujuan ini.

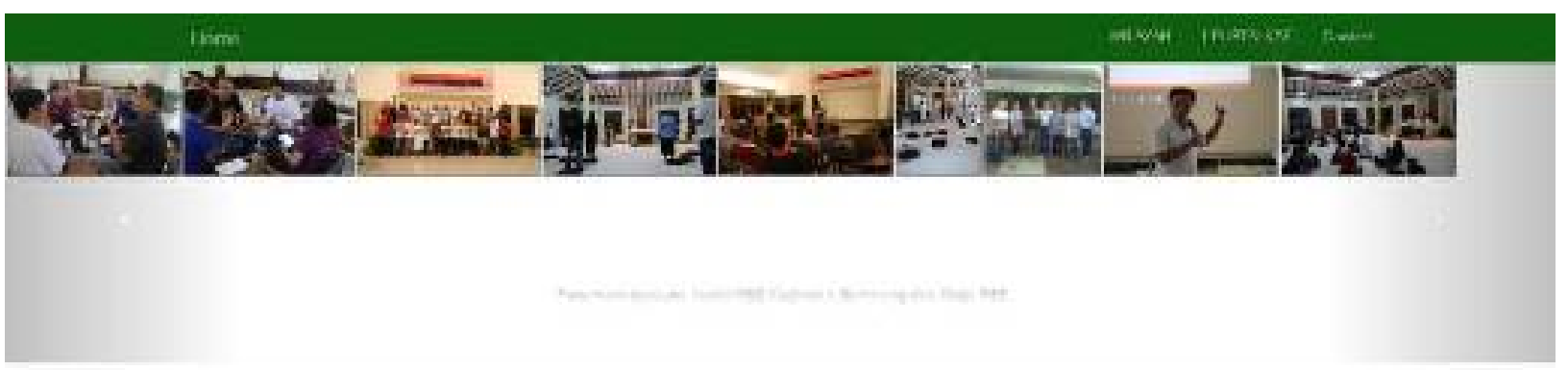

Pelatihan Pertanian ol PSM Muntlian 3-4 Sept 16 Komis|

\section{PSE KA.S}

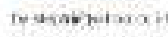

Q $250 \times 000 \cdot 2 \times 13$

$1-\infty x+2$

Sharing LPUBTN OQWISma PoloK

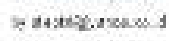

secoserians.

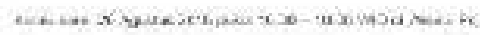

Aatkes:

Pelathan Operasional Web LPUBTN

na...

exiseas

ass rant: : osos.

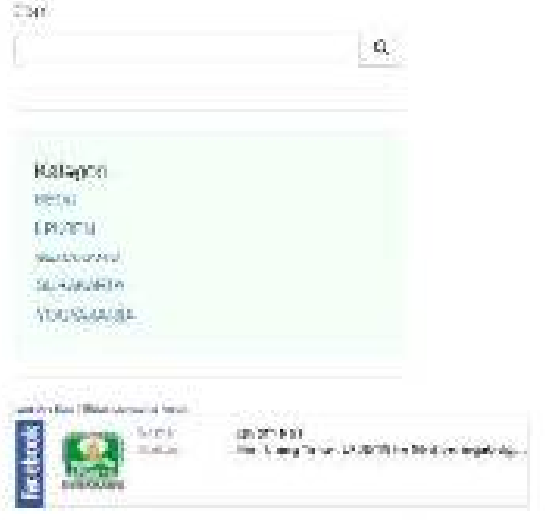

Ixsols remant

GQ

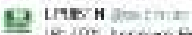

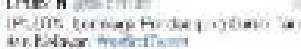

Laes mo vorta

Gambar 1. Halaman depan situs LPUBTN 
Di masa mendatang, pengelola mengharapkan agar gerakan ini dapat diikuti oleh umat di berbagai wilayah di keuskupan Semarang. Situs ini juga diintegrasikan dengan berbagai media sosial seperti Facebook dan Twitter.

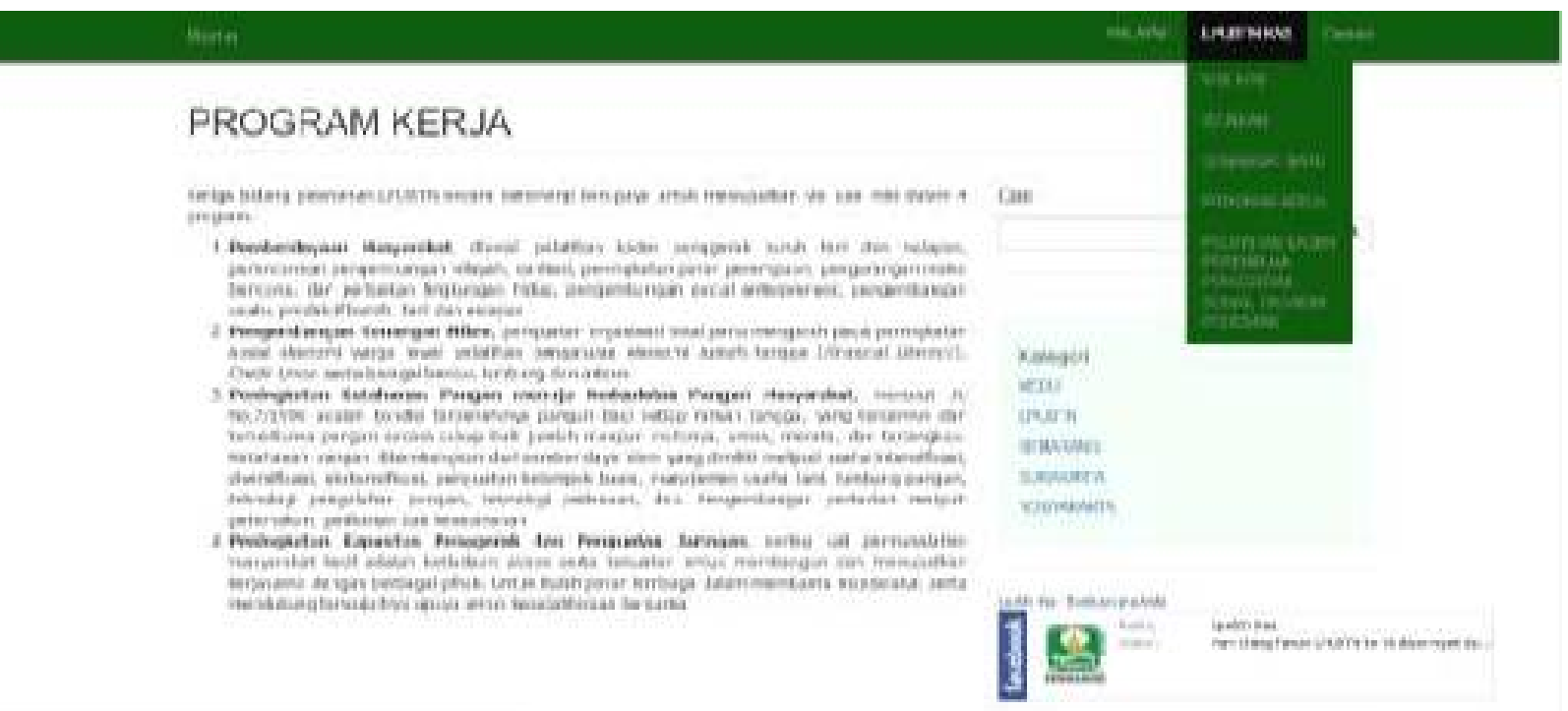

b. Akun Facebook

Gambar 2. Halaman Program Kerja situs LPUBTN

Tujuan dibuatnya akun Facebook untuk LPUBTN adalah untuk lebih memperkenalkan kegiatan bagi umat di Keuskupan Agung Semarang pada khususnya dan masyarakat luas di Semarang dan sekitarnya pada umumnya. Kekuatan akun Facebook ini terletak pada update kegiatan berupa foto dan multimedia video.

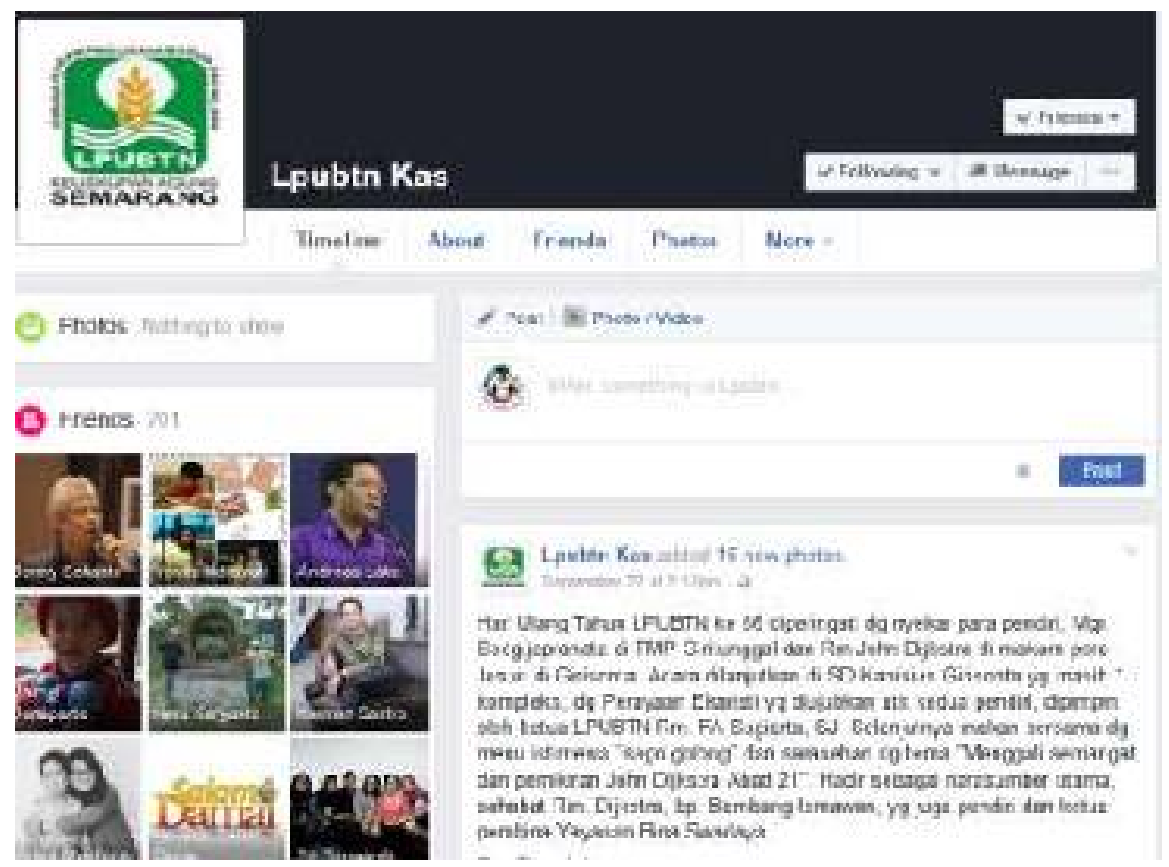

Gambar 3. Akun Facebook LPUBTN 
Guna mendapatkan tanggapan yang lebih luas, akun Facebook diatur "Public" sehingga foto dan penjelasan kegiatan yang dilakukan bisa diakses oleh masyarakat luas.

c. Akun Twitter (@lpubtnkas)

Akun Twitter dibuat untuk melengkapi laman dan akun Facebook. Cover image untuk akun Twitter ini bisa dimodifikasi dan diganti dengan foto program yang terbaru.

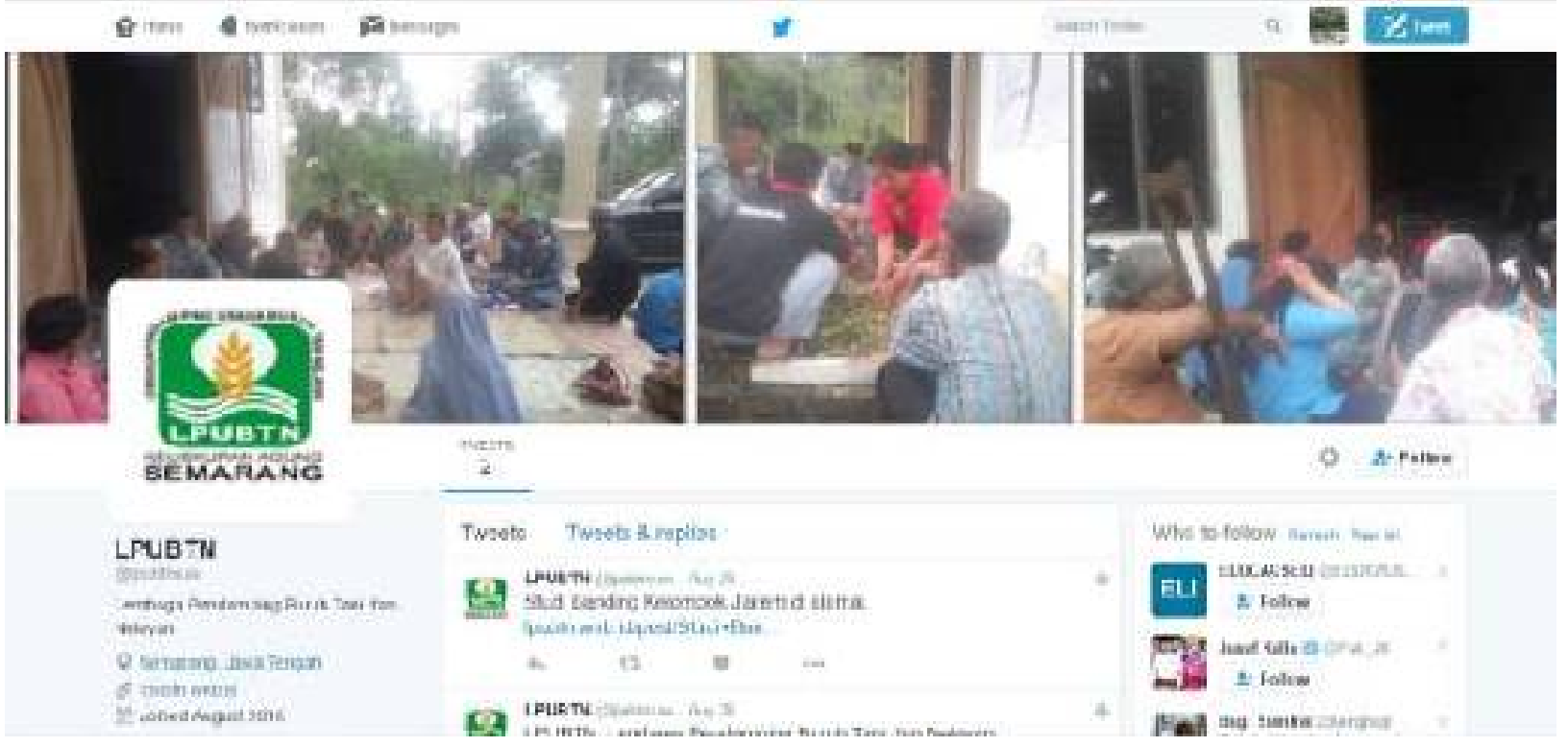

d. Pelatihan

Gambar 4. Akun Twitter LPUBTN (@1pubtnkas)

Agar teknologi informasi ini bisa digunakan oleh masyarakat luas, maka diperlukan adanya pelatihan bagi relawan yang bertugas untuk memperbarui berita kegiatan. Pada tanggal 20 Agustus 2016, tim mengadakan pelatihan pengoperasian situs LPUBTN di kantor LPUBTN. Pelatihan ini diikuti oleh 14 peserta perwakilan dari 4 wilayah di KAS.
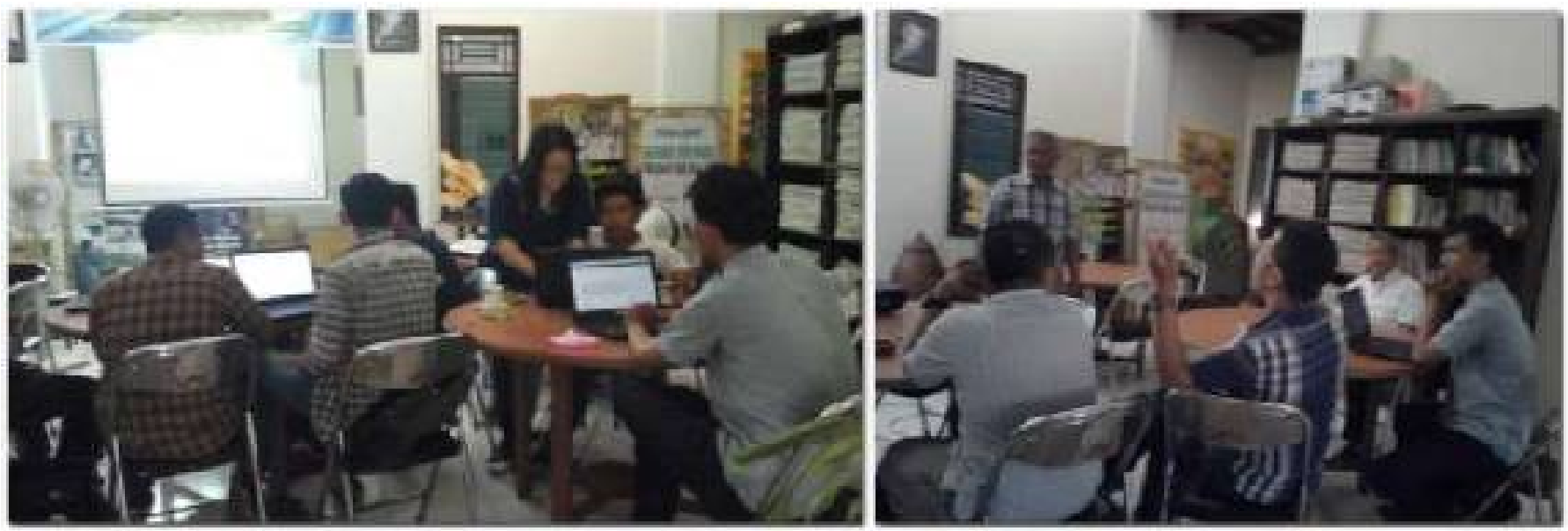

Gambar 6. Ketua tim memimpin pelatihan pengoperasian situas LPUBTN 
Pelatihan ini dibantu oleh mahasiswa Program Studi Teknik Informatika. Peserta pelatihan diharapkan bisa mengoperasikan laman sehingga kegiatan lembaga terbaru bisa di unggah. Guna memudahkan pengoperasian situs, tim juga membuat buku panduan untuk administrator situs.

3 $r>1$
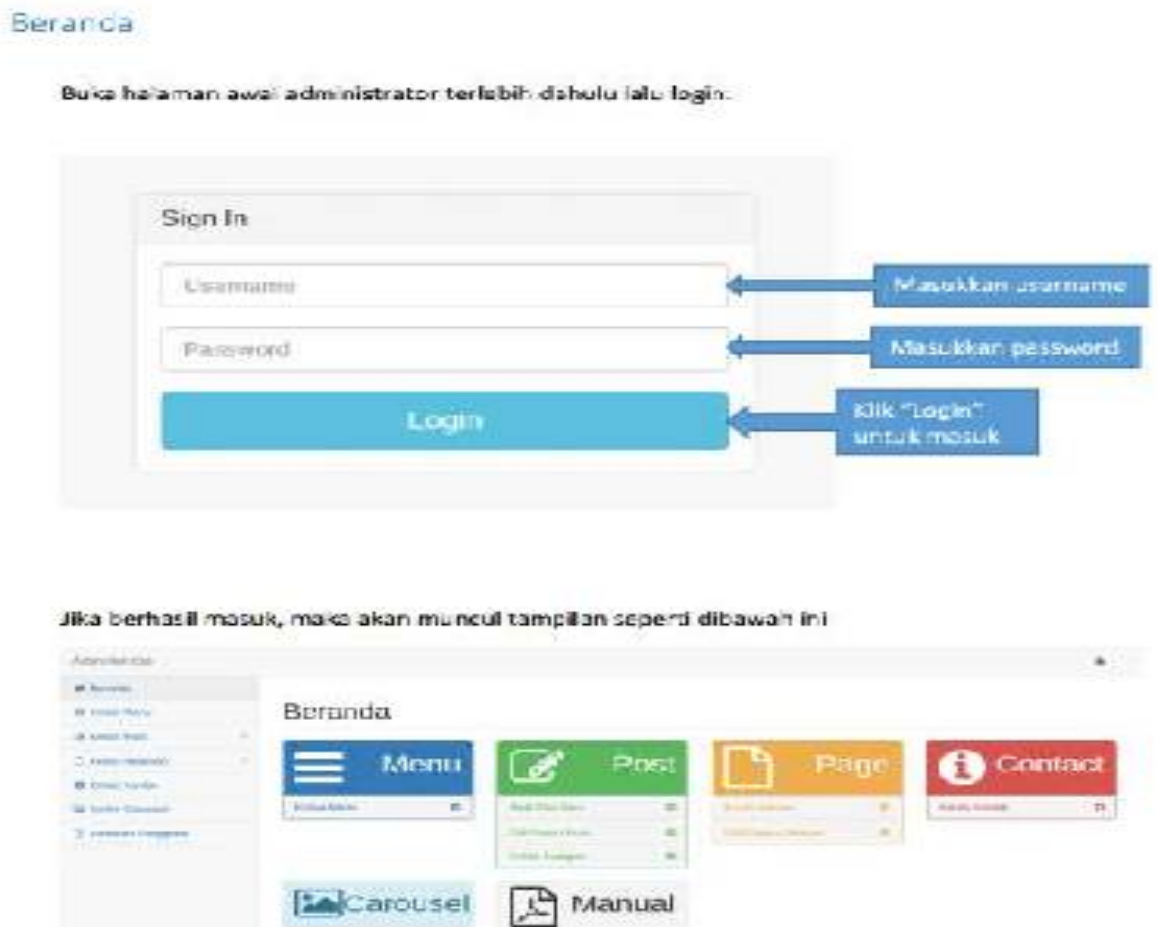

Gambar 7. Buku Panduan Administrator Web

Situs LPUBTN dirancang sedemikian rupa sehingga pengelola situs bisa mengunggah berita beserta foto kegiatan dengan mudah. Tampilan situs dibuat sederhana karena sehingga pengunjung bisa mencari menu yang dicari dengan mudah. Selain itu, berita terbaru dibuat dengan model blog, sehingga pengunjung situs bisa langsung membaca berita terbaru. Fitur Search membantu pencarian berita, dan fitur media sosial langsung bisa mengarahkan pengunjung ke akun Facebook atau Twitter.

Berbagai kendala ditemukan dalam proses pengembangan situs sampai pada pelatihan. Oleh karena peserta pelatihan tidak memiliki latar belakang penguasaan teknologi informasi, maka proses pelatihan membutuhkan waktu yang cukup lama dalam beradaptasi. Kendala lain adalah kemampuan dari peserta dalam mengelola informasi menjadi sebuah berita yang di posting, membutuhkan pendampingan penulisan lebih lanjut.

\section{KESIMPULAN DAN SARAN}

LPUBTN mengembangkan situs sebagai salah satu solusi dalam menggerakan sebanyak mungkin pihak terlibat dalam memberdayakan buruh, tani dan nelayan di bawah naungan KAS. Target yang ingin dicapai dari situs ini adalah berita dan kegiatan gerakan bersama dapat tersampaikan pada seluruh komunitas mengingat luasnya cakupan wilayah kerja dari LPUBTN. 
LPUBTN sebagai sebuah gerakan bersama tentunya membutuhkan cara penyampaian solusi, gagasan dan juga ide-ide dalam pemberdayaan masyarakat. Salah satu cara yang ditempuh adalah dengan memanfaatkan jaringan media sosial dan juga web sebagai sarana penyampaian informasi dan juga laporan keseluruhan kegiatan yang berajalan di bawah naungan LPUBTN. Dampak yang dirasakan langsung oleh seluruh komunitas buruh, tani dan nelayan adalah tersampaikannya informasi kegiatan dari setiap wilayah dapat memberikan inspirasi bagi kegiatan yang diselenggarakan ditempat lain. Pemikiran dan semangat dasar yang tertuang dari Visi dan Misi LPUBTN dapat tercapai salah satunya adalah melalui media situs dan media sosial. Dari keseluruhan kegiatan yang sudah berlangsung, maka perlu dilakukan pengembangan kegiatan pendampingan selanjutnya yaitu bagaimana penyusunan laporan dan berita kegiatan secara baik dan menarik sehingga semua kegiatan LPUBTN dapat dikemas dengan lebih menarik sehingga dapat memperngaruhi semua pihak dalam pergerakan bersama yang digagas LPUBTN dapat tercapai.

\section{DAFTAR PUSTAKA}

Abidin, A. (2016, September 17). Petani Terpinggirkan Investor Asing. Surya Malang. Diunduh dari http://suryamalang.tribunnews.com/2016/09/24/petani-terpinggirkan-para-investorasing

Badan Pusat Statistik. (2016a). IHK dan rata-rata upah per bulan buruh peternakan dan perikanan di bawah mandor (supervisor) Indonesia, 2012-2014. Diunduh dari https://www.bps.go.id/linkTabelStatis/view/id/1453

Badan Pusat Statistik. (2016b). Upah nominal dan riil buruh tani di Indonesia (Rupiah) 20142015. Diunduh dari https://www.bps.go.id/linkTabelStatis/view/id/1465

\begin{tabular}{|l|l|}
\hline Hironimus Leong & Pemaparan makalah sudah sangat jelas, tidak ada diskusi. \\
\hline
\end{tabular}

